\title{
Fully integrated optical system for lab-on-a-chip applications
}

Balslev, Søren; Olsen, Brian Bilenberg; Geschke, Oliver; Jørgensen, Anders Michael; Kristensen, Anders; Kutter, Jörg Peter; Mogensen, Klaus Bo; Snakenborg, Detlef

\section{Published in:}

Proceedings of IEEE MEMS 2004

Link to article, DOI:

10.1109/MEMS.2004.1290529

Publication date:

2004

Document Version

Publisher's PDF, also known as Version of record

Link back to DTU Orbit

Citation (APA):

Balslev, S., Olsen, B. B., Geschke, O., Jørgensen, A. M., Kristensen, A., Kutter, J. P., Mogensen, K. B., \& Snakenborg, D. (2004). Fully integrated optical system for lab-on-a-chip applications. In Proceedings of IEEE MEMS 2004 (pp. 89-92). IEEE. https://doi.org/10.1109/MEMS.2004.1290529

\section{General rights}

Copyright and moral rights for the publications made accessible in the public portal are retained by the authors and/or other copyright owners and it is a condition of accessing publications that users recognise and abide by the legal requirements associated with these rights.

- Users may download and print one copy of any publication from the public portal for the purpose of private study or research.

- You may not further distribute the material or use it for any profit-making activity or commercial gain

- You may freely distribute the URL identifying the publication in the public portal 


\title{
FULLY INTEGRATED OPTICAL SYSTEM FOR LAB-ON-A-CHIP APPLICATIONS
}

\author{
S. Balslev ${ }^{\dagger}$, B. Bilenberg, O. Geschke, A. M. Jorgensen, A. Kristensen, \\ J. P. Kutter, K. B. Mogensen, and D. Snakenborg \\ Mikroelektronik Centret (MIC), Technical University of Denmark (DTU) \\ Ørsteds Plads, Bldg. 345east, DK-2800 Kgs. Lyngby \\ †Email: sba@mic.dtu.dk \\ Web: http://www.mic.dtu.dk
}

\begin{abstract}
We present a lab-on-a-chip device featuring a microfluidic dye laser, wave-guides, microfluidic components and photo-detectors integrated on the chip. The microsystem is designed for wavelength selective absorption measurements in the visible range on a fluidic sample, which can be prepared/mixed on-chip. The laser structures, wave-guides and micro-fluidic handling system are defined in a single UV-lithography step on a $10 \mu \mathrm{m}$ thick SU-8 layer on top of the substrate. The SU-8 structures are sealed by a Borofloat glass lid, using polymethylmethacrylate (PMMA) adhesive bonding.
\end{abstract}

\section{INTRODUCTION}

In order to facilitate efficient optical analysis on lab-on-a-chip microsystems $[1,2]$, the integration of optical transducers is a key issue [3]. In addition to the benefits of miniaturization, the problems associated with optical alignment are strongly reduced, when the optical input and output transducers are integrated on the chip.

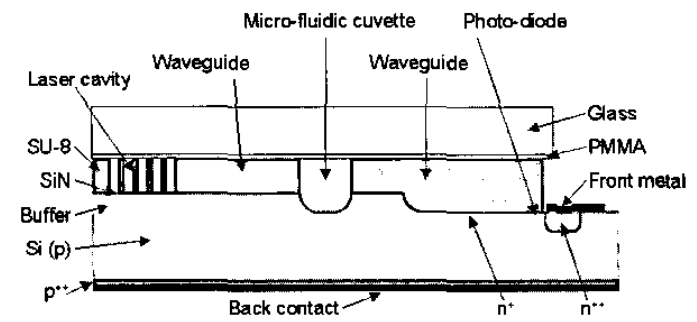

Figure 1: Cross-sectional outline of the lab-on-a-chip device with integrated laser, waveguides, microfluidic components and photodiodes.

In this paper we present a lab-on-a-chip device with laser light source and photo-detectors integrated with wave-guides and microfluidic components. The microsystem is fabricated on a $100 \mathrm{~mm}$ p-type silicon wafer substrate with embedded photo-diodes. A cross- sectional outline of the device is shown in Fig. 1. The laser structures, wave-guides and micro-fluidic handling system are defined in the same $10 \mu \mathrm{m}$ thick SU-8 [5] layer on top of the substrate. The SU- 8 structures are sealed by a Borofloat glass lid, using polymethylmethacrylate (PMMA) adhesive bonding [4]. Fluidic connections are facilitated by holes drilled through the glass lid. The complete micro-system with laser, wave-guides, micro-fluidics and five photo-diodes has a footprint of 15 by $20 \mathrm{~mm}$, as illustrated in Fig. 2 .

\section{MICROFLUIDIC DYE LASER}

The previously presented microfluidic dye lasers [6], where a laser cavity was embedded in a micro-fluidic channel, have been further developed for narrow line, single mode operation and emission in the chip plane for direct coupling into waveguides.

The laser is based on an ethanolic solution of the laser dye Rhodamine $6 \mathrm{G}$, and is optically pumped through the glass lid with a pulsed, frequency doubled Nd:YAG laser (wavelength: $532 \mathrm{~nm}$, pulse-width: $5 \mathrm{~ns}$, repetition rate: $10 \mathrm{~Hz}$ ).

The overall laser structure consists of three elements, two reflectors placed on each side of a $\pi / 2$ phase shift element. The reflectors are formed by an array of channels in the SU-8 where the dye solution can flow, and the phase shift element is made by widening the center channel a quarter of a wavelength. Each channel wall contributes to the laser feedback via the reflection arising from the refractive index difference between SU-8 $(n=1.59)$ and the ethanolic dye solution $(n=1.33)$.

By arranging the walls so as to create constructive interference of the reflected light at a desired wavelength, the reflection back into the cavity becomes large for specific frequencies. Single mode lasing can be obtained, even though the cavity supports multiple frequencies since lasing begins at only one mode, and thereby clamps the roundtrip gain.

In our design, we have formed the laser in the $10 \mu \mathrm{m}$ high SU-8 layer by making 41 channels about $20 \mu \mathrm{m}$ wide and $1 \mathrm{~mm}$ long. The walls between the channels are 


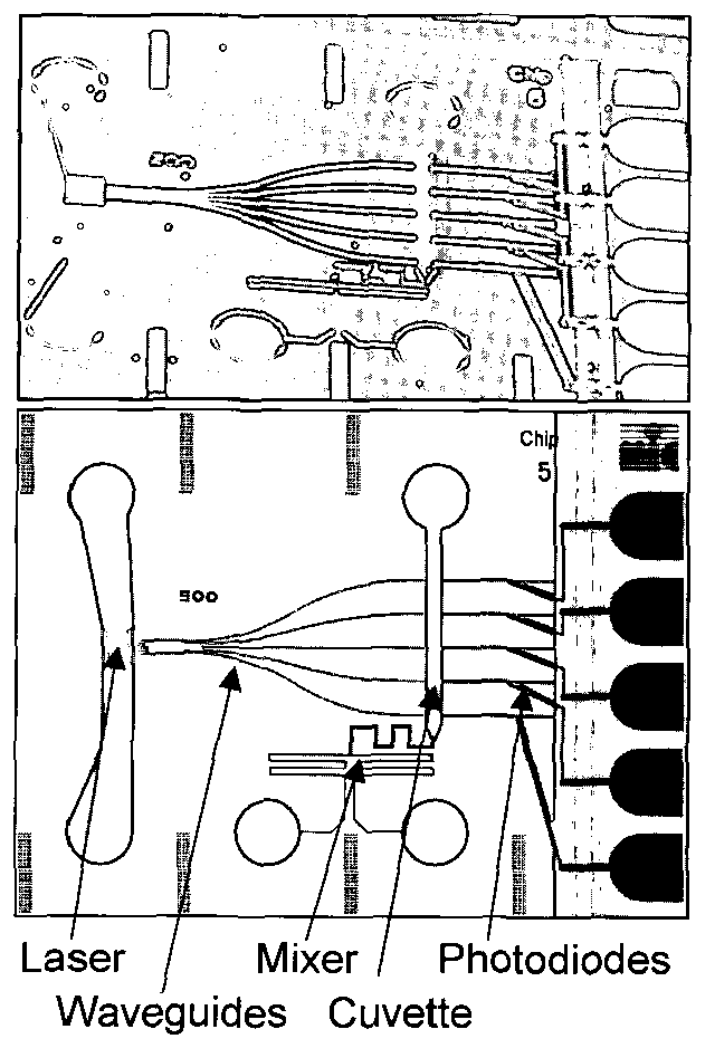

Figure 2: Top: Photo of a lab-on-a-chip device, before bonding the glass-lid. The foot-print of the chip is 15 by $20 \mathrm{~mm}$. Bottom: Mask layout of the device.

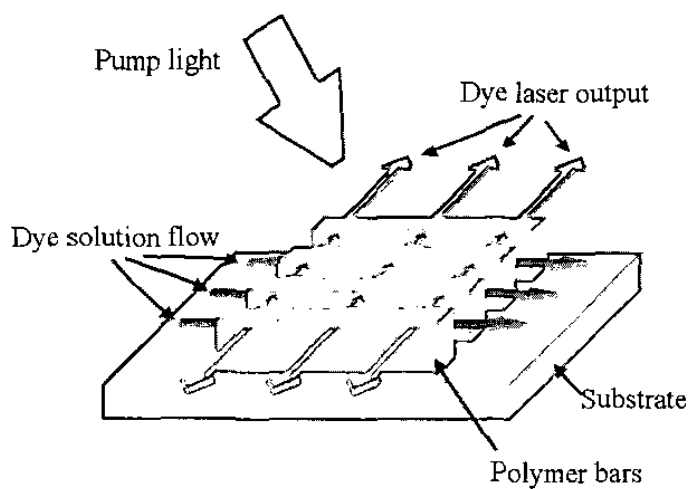

Figure 3: Schematic of the laterally emitting microfluidic dye laser.

likewise about $20 \mu \mathrm{m}$ wide, a size chosen due to limited lithographic resolution. Thus, the laser occupies an area of $1 \mathrm{~mm}$ by $1 \mathrm{~mm}$, excluding the microfluidic channels supplying the cavity with new dye, as the old becomes bleached in the cavity. The flowrate of dye must be larger than $10 \mu \mathrm{L} / \mathrm{hr}$ for a $20 \mathrm{mmol} / \mathrm{L}$ dye solution. The SU-8 sidewalls are vertical within our measuring capabilities, and have a rms sidewall roughness of about $20 \mathrm{~nm}$, as determined by atomic force microscopy.

The output from the laser, coupled into waveguides, exhibits a narrow peak near $573 \mathrm{~nm}$ (unresolved by the spectrometer). Figure 4 shows the spectrum for a typical laser at $50 \mathrm{~mW}$ average pump power. The power was measured with a calibrated diode to be more than $3.5 \mathrm{nW}$ coupled into each waveguide, enough for efficient detection. The lasers exhibited lasing already at $1 \mathrm{~mW}$ pump power. Scattered pump light from the frequency doubled Nd:YAG laser at $532 \mathrm{~nm}$ amounts to less than $4 \%$ of the waveguide coupled light.

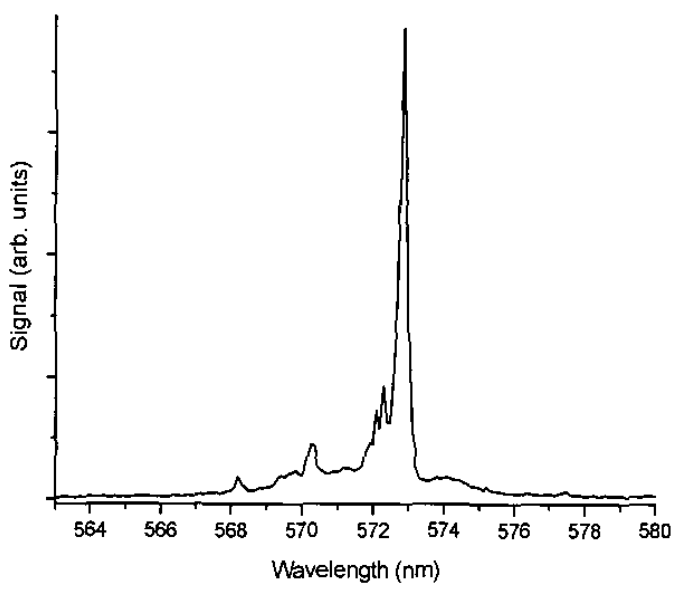

Figure 4: Emission spectrum from the laterally emitting microfluidic dye laser. The single line width reflects the $0.5 \mathrm{~nm}$ spectrometer resolution.

\section{WAVEGUIDES}

The emitted dye laser light is coupled directly into five $30 \mu \mathrm{m}$ wide, $10 \mu \mathrm{m}$ high SU-8 waveguides, and guided to the microfluidic channel network. Integration of fluidic channels and polymer waveguides has been presented elsewhere [7]. The fraction of light transmitted across the fluidic channel is collected by waveguides that are connected to integrated photodiodes for detection. The five waveguides for collection of the laser light are placed with a center-to-center spacing of $80 \mu \mathrm{m}$ and thereby span a region of $350 \mu \mathrm{m}$ at the position of the dye laser. Bends are incorporated in the waveguides in order to achieve a $1.0 \mathrm{~mm}$ spacing between the detection points along the fluidic channel (cuvette), see Fig. 2. It was not necessary to use a waveguide beamsplitter for multiple point detection, because the laser emits in a relatively large area. This is advantageous in terms of transmitted optical power, since beam-splitting, and thus division of the light intensity, is avoided. The distance between the exit of the dye laser and the microfluidic cuvette is $9.2 \mathrm{~mm}$. 


\section{MICROFLUIDIC MIXER AND CU- VETTE}

The microfluidic channels consist of a diffusion mixer and a channel for absorbance detection, see Fig. 2. This simple network allows a reaction of two reagents and detection of the product at multiple points. The dimensions of the channels are chosen so that the fluidic resistance before the mixer is larger than in the rest of the network, in order to be able to control the mixing. The inlet channels to the mixer have a width of $50 \mu \mathrm{m}$ and a length of $8.0 \mathrm{~mm}$, while the mixing channel is $100 \mu \mathrm{m}$ wide and $5.7 \mathrm{~mm}$ long. The detection channel has a width of $500 \mu \mathrm{m}$ and a length of $6.5 \mathrm{~mm}$. An absorbance length of $500 \mu \mathrm{m}$ was chosen, based on previous experience [7], in order to secure a reasonable signal-to-noise ratio of the detection.

\section{PHOTODIODES}

The photodiodes on the chip are vertical junction photodiodes (see Fig. 1) using a p-type substrate. The active area was $50 \mu \mathrm{m}$ by $2 \mathrm{~mm}$ (see Fig. 2), in order to achieve an efficient coupling of light from the waveguides to the photodiodes. Leaky wave coupling was preferred over end-fire coupling [8] due to the much easier processing of leaky wave couplers [9]. The photoactive junction was realized with a $n^{+}$phosphorous doping. Highly $n^{++}$doped contact areas were also made to allow for ohmic contacts. To prevent surface inversion due to boron segregation, boron doping was performed on the front surface where there were no phosphorous dopings. To facilitate ohmic contact to the back side of the wafer a heavy boron doping was performed over the whole wafer surface.

The photodiodes were coated with a hydrogenated silicon nitride coating known to effectively passivate phosphorous doped regions [10]. The silicon nitride film was deposited by PECVD and contact holes were etched using hydrofluoric acid [11]. Front side electrodes were fabricated using a sandwich of titanium and aluminum. The backside metal was aluminum. After the metal was deposited and patterned the wafers were annealed in a forming gas: $4 \% \mathrm{H}_{2}$ by volume in $\mathrm{N}_{2}$ at $400^{\circ} \mathrm{C}$.

\section{PACKAGING}

The chip was mounted in a polycarbonate sample holder with electrical and fluidic connections, as shown on Fig. 5.

The fluidic connections are sealed by o-rings, and teflon tubes were connected to the sample holder by LEE MINSTAC fittings. Spring loaded probes from Harwin, were used to make pressed contacts to the connector pads on the chip. A window in the polycarbonate lid gives optical pumping access to the micro-fluidic dye

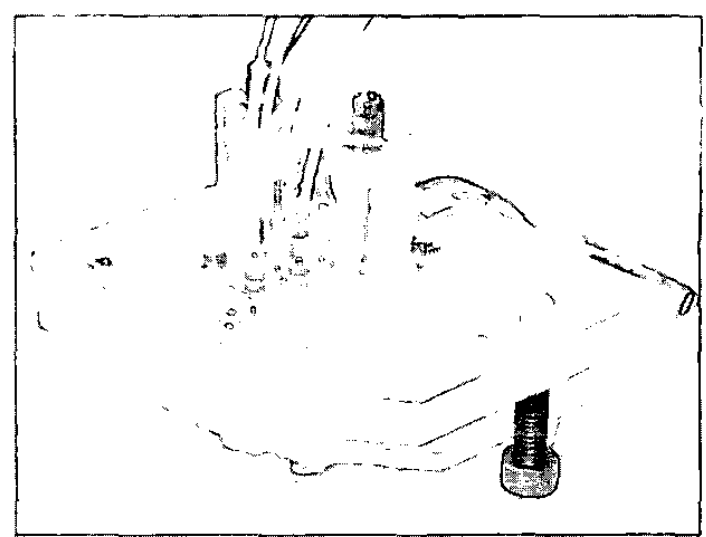

Figure 5: Chipholder with fluidic and electrical connectors for the lab-on-a-chip microsystem with integrated microfluidic dye laser and photo-diodes.

laser.

\section{RESULTS}

The emission from the dye laser was measured using a spectrometer with a $0.5 \mathrm{~nm}$ FWHM response. Figure 4 shows a spectrum taken with a pump power of $50 \mathrm{~mW}$. The laser line at $572.9 \mathrm{~nm}$ has a linewidth below the resolution limit of the spectrometer. The pump residue from the Nd:YAG laser (at $532 \mathrm{~nm}$ ) coupled into the waveguide has an intensity $<-30 \mathrm{~dB}$ of the dye laser light. The lasing threshold is $<1 \mathrm{~mW}$.

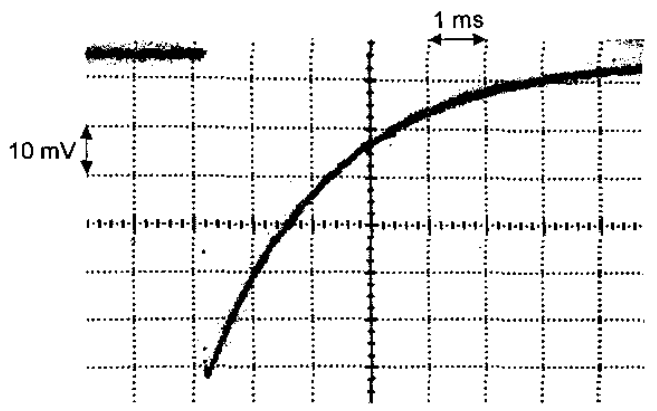

Figure 6: Open circuit photo-diode response from a single microfluidic dye laser pulse.

The quantum efficiency of the photo-diodes was measured to values above $80 \%$. Furthermore, they show a noise equivalent power $(\mathrm{NEP})<1 \mathrm{pW}$, when operated in short-circuit mode for low noise performance. This enables a $\mathrm{S} / \mathrm{N}$ ratio on the order of 5000 for the integrated optical system on the chip. A measurement of the open circuit diode response from a single dye laser pulse is shown in Fig. 6. 


\section{Acknowledgements}

This work was supported by the Danish Technical Research Council, STVF (grant numbers: 26-00-0220 and 26-02-0064).

\section{References}

[1] A. Manz, N. Graber, and H.M. Widmer, Miniaturized total chemical analysis systems: a novel concept for chemical sensing, Sens. Actuators B, 1, pp. 244248 (1990)

[2] S. Verpoorte and N.F. De Rooij, Microfluidics meets MEMS, Proceedings of the IEEE, 91, pp. 930-953 (2003)

[3] S. Verpoorte, Chip vision-optics for microchips, Lab Chip, 3, pp. 42N-52N (2003)

[4] B. Bilenberg, T. Nielsen, D. Nilsson, B. Clausen, and A. Kristensen, PMMA to $S U-8$ Bonding for Polymer Based Lab-on-a-chip Systems with Integrated Optics, Proceedings of the 17th European Conference on Solid-State Tranducers, Eurosensors 2003, Guimarães, Portugal, September 21 - 24, pp. 486-489 (2003)

[5] XP SU-8 photoresist and PGMEA developer from MicroChem Corp.

[6] A Micro-Cavity Fluidic Dye Laser, B. Helbo, A. Kristensen and A. Menon, Journal of Micromechanics and Microengineering, vol. 13, Issue 2, pp. 307$311(2003)$

[7] Integration of Polymer Waveguides for Optical Detection in Microfabricated Chemical Analysis Systems, K. B. Mogensen, J. El-Ali, A. Wolff, J. P. Kutter, Applied Optics, 42 (19), pp. 4072-4079 (2003)

[8] O. Leistiko and P. Friis, Bio/Chemical microsystems with integrated photodiode arrays of improved sensitivity and functionality, Proc. SPIE Micro- and Nanofabricated Structures and Devices for Biomedical Environmental Applications II, San Jose, California, pp. 10-19 (1999)

[9] M. Moreno, C. Domínguez, J. Munoz, J. Calderer, and J.R. Morante, Photosensor and optical waveguide coupling in silicon technology, Sensors and Actuators A 62, pp. 524-528 (1997)

[10] M.J. Kerr, J. Schmidt, A. Cuevas, J.H. Bultman, Surface recombination velocity of phosphorusdiffused silicon solar cell emitters passivated with plasma enhanced chemical vapor deposited silicon nitride and thermal silicon oxide, Journal of Applied Physics, 89, pp. 3821-3826 (2001)
[11] F.E. Rasmussen, B. Geilman, M. Heschel, O. Hansen, and A.M. Jorgensen, Development and characterisation of $K O H$ resistant $P E C V D$ silicon nitride for microsystems applications, Proc. First International Symposium on Science and Technology of Dielectrics in Emerging Fields, Paris, France, pp. 218-229 (2003) 